\title{
The End or the Means? \\ The Pursuit of Competition in Regulated Telecommunications Markets
}

June 2008

Bronwyn Howell

Presented at the International Telecommunications Society $! 7^{\text {th }}$ Biennial Conference, Montreal, Canada, June 24-27, 2008.

New Zealand Institute for the Study of Competition and Regulation Inc. and Victoria Management School, Victoria University of Wellington, PO Box 600, Wellington, New Zealand. Email bronwyn.howell@vuw.ac.nz

Acknowledgement: The author acknowledges the helpful comments of Glenn Boyle and Lewis Evans in the preparation of this paper. The views expressed are solely those of the authors, and do not necessarily represent those of any ISCR member institutions. Any errors or omissions remain the responsibility of the author. 


\section{Abstract}

Economic analysis takes as its defining performance benchmark the pursuit of increases in welfare (efficiency). Competition is merely one of a variety of means of achieving the efficiency end, especially in industries where the underlying economic circumstances predispose them towards greatest efficiency when competition (in the form of many market participants) is restricted. Typically, regulatory intervention in these industries is justified by the imperative to increase efficiency. Competition law and industry-specific regulation provide two competing means of intervention whereby the pursuit of efficiency can be enhanced. The challenge is in determining how to allocate responsibility for governance of industry interaction between these two institutional forms. Whilst competition law can govern interaction in most industries, where the underlying economic conditions are sufficiently different, industry-specific regulation offers advantages. However, its weakness is the risk of capture, leading to the subjugation of the efficiency end to the pursuit of other objectives (e.g. competition - the means - as an end in itself). But if the regulatory institution could be bound in some way to pursue an efficiency objective, could the risk of capture be averted?

By exploring the attempts to prioritise the pursuit of efficiency via both competition law and industry-specific regulation in New Zealand over the past twenty years, this paper concludes that such an endeavour is unlikely to be successful in the long run. As politicians ultimately control the rules by which the regulatory responsibilities are allocated, and politicians are themselves pose a potential risk of capture for the industry-specific regulatory processes, the inability of a government prioritising efficiency objectives to bind its successors to the same objectives means that the efficiency objective is not stable. From the New Zealand experience, the outcome could be total subjugation of industry-specific regulation to direct political control and the abandonment of efficiency as a primary regulatory objective. This suggests that, imperfect though it may be, competition law overseen by a judiciary with greater independence of the political process, offers the best chance of enshrining pursuit of efficiency into the governance of industry interaction, even in industries normally the focus of industry-specific regulation. 


\section{Competition or Regulation?}

Economic analysis takes, as its defining performance benchmark, the pursuit of increases in efficiency (welfare), measured as the sum of consumer and producer (i.e. total) surplus. In this paradigm, an increase in total surplus is strictly preferable to the status quo or a decrease in total surplus. An action that brings about a greater efficiency increase is therefore strictly preferable to one leading to a lesser increase, maintains the status quo, or leads to a decrease. In this context, the primary normative objective of law- and policy-making is the promotion of economic efficiency via the elimination of market efficiencies (Schmalansee, 1979; Kahn, $1970 ; 1975)$.

Whilst a minority of economists, and many consumer advocates, propose the use of law- and policy-making powers principally as a means of achieving distributional objectives independent of their effects upon total efficiency (e.g. Feldstein, 1972a; 1972b), their use for this purpose is extremely difficult to achieve in practice (Schmalansee, 1979), and possibly counter-productive (Kahn, 1975; Peltzman, 1976). Furthermore, as distributional objectives are highly subjective, it is very difficult to adjudge the 'success' of any distribution-motivated intervention. By contrast, efficiency is an objective measure that provides a useful benchmark for the economic assessment of law- and policy-making performance, even if redistribution is a primary consideration. The Kaldor-Hicks criterion holds that if total welfare (efficiency) is greater as a consequence of a law or policy change, then the gains to the winners will be greater than the losses incurred by the losers, and the change economically justified, irrespective of whether the gains are actually shared (i.e. redistribution occurs) (Connolly \& Munro, 1999).

Consequently, the pursuit of increased efficiency is broadly accepted as the principal economic justification for the enactment of competition (antitrust) law overseen by courts and judges and industry-specific regulation, overseen by regulators and regulatory agencies (Carlton \& Perloff, 2005). In the United States context, since the passing of the Interstate Commerce Act (1897) and the Sherman Act (1890), "regulation and antitrust have operated as competing mechanisms to control competition” (Carlton \& Picker, 2007:1). The challenge for law- and policy-makers is in determining a balance in the allocation of responsibilities between the courts enforcing the generic antitrust obligations of firms and regulatory authorities overseeing efficient operation within specific industries where underlying economic characteristics predispose them to efficiency limitations, in a manner that best promotes the pursuit of increased efficiency. 


\subsection{Courts or Regulators?}

It is far from clear that either the courts or industry-specific regulatory bodies have embedded in their legislative underpinnings or operational capacities the ability to take full account of all relevant issues of economic efficiency. Carlton \& Picker (2007) suggest that the development of an independent United States jurisprudence has enabled economic principles to be increasingly included in judicial decision-making, in a manner that is not possible in less-independent industry-specific regulation.

However, whilst court-governed processes can give weight to promoting increases in economic efficiency, they are constrained in their ability to promote its maximisation under the prevailing constraints. Courts are reactive, responding only to those cases and those points of law brought before them. Judges have no mandate to address potentially efficiencyraising issues that market participants choose not to pursue in litigation. Their decisions thus lead to incremental changes over a small range of issues, which are not necessarily the most important from a broader efficiency perspective.

Moreover, even when cases are brought, they are adjudicated by generalist antitrust judges who in most cases lack the industry-specific economic knowledge upon which efficiency decisions may turn. The quality of the judgements is conditional upon the quality of advice available (e.g. access of the panel to expert lay members) and the analysis and range of issues presented by the litigants. The precedents set in jurisprudence also hinge upon the economics of the test cases. Precedents formed upon the basis of underlying economic characteristics in one industry may not transfer neatly into industries where different underlying economic characteristics prevail. For example, high fixed and sunk costs induce a different form of competitive interaction between industry participants, and different efficiency outcomes, than where these cost are low or non-existent. For example, whereas competitive behaviour favouring a large number of market participants driving price towards marginal cost raises efficiency in most industries, where sunk costs are large, injudicious entry and pursuit of marginal cost pricing creates, rather than ameliorates, market failure with its associated loss of efficiency (Carlton and Perloff, 2005).

The risks of judicial economic error associated with economically 'different' industries predominantly the network industries such as telecommunications, electricity, railways, airlines and other transport - suggest that the creation of industry-specific regulators to govern industry interaction has the potential to improve decision-making and is indeed an economically rational response to the limitations of jurisprudence. Industry-specific 
regulators in most cases have the requisite economic knowledge to give due weight to efficiency considerations. They can also be given a much broader mandate to investigate issues which in their judgement warrant attention. Rather than being reactive, they can be proactive - a power that when applied appropriately can lead to increases in efficiency. Proactive power thus tends towards more radical industry change in regulator-governed regimes than is observed in antitrust-governed ones, enabling the capture of efficiency gains in a more-timely manner than is possible under court-governed processes.

However, unlike judges who in most jurisdictions are independent of political processes, regulators' comparative lack of independence exposes them to greater risk of capture, either by either the politicians who grant them authority in the first place, or industry participants, with whom they are most closely associated in their daily activities, and whose livelihoods depend upon the regulator's decisions. This predisposes regulatory decisions towards a greater emphasis upon redistributive rather than economic efficiency issues. The measure of a regulatory regime's effectiveness and ability to deliver upon the efficiency objective turns upon firstly the extent to which it is charged with the pursuit of economic efficiency, and secondly the regulator's ability to adhere to the efficiency objective in the face of pressures which will inevitably come to bear upon it to deviate towards favouring specific redistributive desires.

\subsection{Regulation to Promote Competition?}

Striking a balance in the allocation of industry governance responsibilities between competition law and industry-specific regulation assumes considerable importance when industry-specific regulatory policy derives its mandate from the pursuit of increased efficiency through the mechanism of increased competition. As competitive interaction takes on many different forms, industry economic characteristics will determine the appropriate form against which industry performance must be tested in order to ensure the efficiency objective is furthered. Starting from the presumption that competition law promotes competition because competition increases efficiency, and that industry-specific regulation exists in some industries because competition law alone in inadequate for delivering timely efficiency improvements due to different economic characteristics that lead to a different set of interactions in order to achieve optimal efficiency, then a regulatory agency inducing competition in such an industry must of necessity be inducing competition of a different form (e.g. oligopoly/monopolistic competition) than would have prevailed otherwise (e.g. perfect competition). 
Is it feasible, therefore, to presume that regulator-induced competitive activity could ever be subject to the same legal processes and precedents as pertain to other industries, as long as the different underlying economic characteristics prevail? It would seem that the answer lies in the ability of the courts to have access to sufficient industry-specific economic analysis to understand the differences between regulator-induced competitive interaction and endogenous competitive interaction. Sidak (2008) illustrates conflicts arising in different jurisdictions regarding the legality of 'price squeezes' induced by regulatory duties to deal that would not occur normally in an unregulated market. Economic analysis incorporating the upstream origin of the 'squeeze' arrives at a different efficiency finding than analysis taking as its starting point only the action in the downstream retail product market. Whilst a sufficiently well-informed court may be able to make an efficiency-raising decision, Sidak’s comparison of the range of different judgements arrived at by courts in different circuits in the United States and in the European Union on essentially the same facts suggests that it is not at all clear that courts in all jurisdictions are capable at the current point in time of acting with consistently in a manner that promotes efficiency given the economic complexities attendant to the different forms of competition induced by regulatory intervention.

\subsection{Does Regulation to Promote Competition Always Enhance Efficiency?}

By derivation, a second key consideration in the allocation of industry governance responsibilities hinges on the types of competitive interaction induced by regulators. Whilst the economic motivation for the assignment of responsibility to regulatory bodies lies in the potential to apply industry-specific economic understanding for the pursuit of increased efficiency, the risk exists that regulatory powers can be captured by strong stakeholders and used for the pursuit of other (especially redistribution) agendas. A particular risk attends the pursuit of competition as an objective in its own right. Is it rational to substitute pursuit of competition as a regulatory objective on the presumption that it is a proxy for the pursuit of efficiency?

Crucially, the appropriateness of the competition objective for regulated industries lies not in the pursuit of static 'perfect competition' where it is presumed that the number of participants producing an homogeneous good is infinite and price is driven to marginal cost, but in the pursuit of alternative competitive processes that take into consideration the cost structures of industries with high fixed and sunk costs, and the dynamic incentives associated with a smaller number of firms investing very large sums in differentiated technologies across time (Alleman \& Rappoport, 2005). If the different economic standards did not prevail, then ipso 
facto, it would be unnecessary to delegate responsibility to a regulatory agency in the first place. Competition law governance would suffice.

\subsection{Privatisation and the Pursuit of Competition}

A third consideration attends the simultaneous forces of competition, regulation and privatisation. Regulating an historically government-owned natural monopoly interlaces a 'competition' imperative with the 'privatisation' imperative in a manner that exposes the regulatory process to even greater pressure to take account of distributional considerations than might normally be the case. Whilst privatisation is pursued in the first place to increase efficiency, it is not strictly necessary that privatisation must be twinned with competition, unless the competition pursued is of a form that promotes ongoing efficiency gains. Moreover, combining the two objectives into one policy action invokes the classic tension between competing objectives, where the best-rewarded objective will prevail (Holmstrom \& Milgrom, 1991). This is further complicated by the need to secure a political mandate to undertake either action, leading to the risk that a third, non-efficiency objective will prevail. The risk of the efficiency objective being even further diluted is increased if the prioritisation is undertaken by politicians even less well informed about the economic consequences of their actions than judges or regulators.

For example, the competitive incentives for industry entry are driven by the pursuit of profits. Yet in order to secure a mandate for privatisation, politicians typically bind the privatised incumbent with social obligations (e.g. universal service) and pricing restraints (e.g. caps, mandatory cost-based prices) which constrain the incumbent's profits and alter its incentives relative to those of competitors should pursuit of competition be a concurrent policy objective. Different treatment of the incumbent and its competitors in the face of competition is a redistributive imperative, and effectively relegates pursuit of efficiency to a secondary role, at least in the short-term. Pursuit of redistribution is further exacerbated if competitive entry occurs as a consequence of arbitrage based upon regulatory restrictions on the incumbent rather than as a consequence of more efficient production processes or welfareenhancing product differentiation. Politicians are predisposed to lobbying by interested parties for purely redistributive purposes, and are poorly equipped to appraise the complex economic consequences of redistributive trades upon the efficiency objective. Inappropriately conflating pursuit of competition measured solely as competitive entry with pursuit of efficiency is therefore more likely to occur, exacerbating the potential of self-interested motivations amongst politicians as agents of voters favouring the pursuit of competition simply because 'evidence' in the form of decreased incumbent market share is very visible in 
the short-run political (voting) horizon, whereas efficiency improvements are less tangible, broadly spread and take time to accrue.

In the longer-run, the effects upon dynamic efficiency of competition pursued for its own sake may be profoundly detrimental. Short-run entry pursued for redistributive or static efficiency purposes without due consideration of long-run dynamic investment and efficiency incentives is counter-productive (Hausman, 1999; Crandall, Ingraham \& Singer, 2004; Pindyck, 2004; 2005; Guthrie, 2007). Greater dynamic efficiency gains may be achieved by preventing, rather than encouraging, competitive entry (e.g. regulatory holidays - Gans \& King, 2004). Likewise, entry induced by the imposition of asymmetric obligations upon the incumbent (e.g. universal service obligations distorting price signals and inducing entry by participants with higher costs than the incumbent; service-level entry on the basis of arbitrage on regulated access tariffs) is unlikely to be either efficiency-raising (Quigley, 2004) or sustainable long-term (e.g. as evidenced by the 'price squeeze literature - Sidak, 2008).

\subsection{An Institutional Solution?}

In summary, therefore, three issues appear to bear materially upon the decision of how to allocate industry governance responsibilities between courts and regulators in order to promote the pursuit of efficiency:

1. some industries are so economically different that different treatment is warranted

2. the competitive interaction in these industries is, by dint of their economic differences, sufficiently different from that in other industries that different tests should apply

3. the pursuit of competition in the economically different industries is complicated by the simultaneous pursuit of privatisation, leading to potential conflicts in agendas and the risk that efficiency will be subjugated to other objectives, and especially the pursuit of a particular form of competition that is incompatible with increasing efficiency in the industry in question.

If the competition means pursued is a poor proxy for the pursuit of the desired efficiency end, and the risk of subversion of the primary objective in pursuit of alternative outcomes is high, the question must be asked whether the pursuit of competition should form any part of a regulatory mandate. Again, the answer is not straightforward. The principal difficulty lies in the application of a process, and is not necessarily inherent in the institutions themselves. Courts are constrained in their mandate to address important efficiency issues by the limitation that they address only the issues brought before them. Regulators are constrained 
because their wider mandate exposes them to greater risk of capture. Politicians are a key source of the risk of capture, by the very nature of their powers allows them to capture the regulatory process. If a regulatory body could be established with an explicit, transparent and accountable objective to undertake its activities giving full weight to efficiency considerations, in each of their productive, allocative and dynamic dimensions, then it might be feasible to strike a balance between the pursuit of competition within the confines of the industry's underlying economic characteristics, in a manner that complements the parallel consideration accorded to efficiency in competition law jurisprudence.

However, under agency theory, to be successful in its pursuit of efficiency, the regulatory body, as agent of the government that creates it, must be able to stand firm against the potential of capture by the government, which will necessarily have its own redistributive agendas. As elimination of the regulator's ability to effect redistributive goals will likely intensify the degree of self-interested lobbying directed at politicians, the risk of government capture will intensify. The political principal holding formal power to direct the regulatoragent is also agent of the wider public, which has imposed the duty to act in a manner that increases total welfare, but is itself subject to self-interested action. To withstand formal political power and remain true to the efficiency objective, the regulatory body must be able to exhibit the same degree of political independence that characterises the judiciary. To do so appears to necessitate regulatory bodies having the same degree of constitutional separation from political imperatives as enjoyed by the courts. Only then would it appear that due weight can be given to efficiency considerations in regulatory-governed processes. Yet enacting such a change requires the political participants to suspend their natural inclinations to further their own position, so it is unlikely to occur. As the New Zealand case study will show, even when one exceptional government does suspend its self-interest to prioritise the pursuit of efficiency, its inability to bind future governments renders the change unstable.

Flawed though the processes may be, court-governed competition law - in the form of an institutional second-best - appears to offer greater assurance that the pursuit of efficiency will be the prevailing objective in industries that would otherwise appear to lend themselves to industry-specific regulation.

\section{The New Zealand Telecommunications Case Study}

New Zealand telecommunications regulation from 1987 to the present offers a cogent example of the vulnerability of even those regulatory agencies designed with economic efficiency objectives in mind to capture by political principals in order to pursue alternative 
objectives. In the New Zealand example, over time the pursuit of competition as a political priority has prevailed over pursuit of efficiency, even though efficiency was explicitly articulated initially as the prevailing political objective, and reliance upon competition law alone was the starting point for the allocation of industry regulatory governance. Even when an industry-specific regulator was established and pursuit of efficiency was afforded weight in the body's legislative mandate, pursuit of efficiency was exposed, and succumbed eventually to politically-motivated subjective redistribution.

Whereas typically, political capture of regulatory processes occurs informally as covert exertion of pressure and influence, the New Zealand case illustrates that statutory expression of the intention to prioritise efficiency as a key regulatory objective has resulted in the capture becoming formalised as overt political action. Political dissatisfaction with both court adjudications and regulatory recommendations based upon efficiency criteria has resulted in a third body - the office of the Minister of Communications and the affiliated Ministry of Economic Development - assuming responsibility for a range of functions normally delegated to the purview of an industry-specific regulator. In the absence of legislative or constitutional formalisation of this action, it is not clear whether the result is intended as competition for or a complement to competition law and regulation. What remains clear, however, is that to date political decision-making has given very little weight to efficiency considerations, has reduced industry certainty as it lacks precedents, and is subject to few of the checks and balances of either competition law or regulatory processes.

\subsection{Efficiency Underpins 'Light-handed' Regime}

New Zealand led the world in 'light-handed' regulation when from 1984, the government embarked upon a comprehensive restructuring of the country's economy. The clearly articulated objective of increasing economic efficiency and creating "wherever possible, a competitive environment in which markets can operate relatively free from subsequent intervention by government” (Evans, Grimes, Wilkinson \& Teece, 1996:1863). As part of this process, he Commerce Act 1986 was enacted with the objective of promoting competition for the long-term benefit of consumers and the Telecommunications Act 1987 eschewed industry-specific regulation in favour of generic competition law under the provisions of the Commerce Act.

Efficiency considerations were paramount in the choice of institutional mechanisms for industry governance. As a small economy with only a little over 4 million people, New Zealand could access economies of scale in the regulatory process itself if a single institution 
governed all commercial activity. The costs, inflexibility and bureaucratic capture weaknesses were explicitly identified as avoidable under a competition law regime (MoC/Treasury, 1995; Blanchard, 1995). Whilst the limitations attendant with non-specialist judges existed, it was also clear that New Zealand's specific economic circumstances - small population, low population density, geographical isolation, challenging terrain, thin capital markets and historically highly-concentrated industries -posed challenges to the enactment of competition law not faced in other jurisdictions (Arnold, Boles de Boer \& Evans, 2003). On balance, the establishment of a single institution to capture scale economies as well as ensure consistency in application was favoured. However, Part IV of the Commerce Act explicitly provided for the government to impose price controls in industries where market power existed, should this be deemed necessary.

Although 'lightly-regulated, the telecommunications sector was far from unregulated. When the state-owned monopoly incumbent was privatised in 1990, contractual obligations known as the 'Kiwi Share' (subsequently the Telecommunications Service Obligation or TSO) imposed rural-urban and free local calling universal service obligations and a price cap on residential line rentals that could be broken only with the express permission of the Minister, and even then only where it could be demonstrated that the incumbent was under financial duress. The paramount principle was that contractual agreement, rather than overt regulation, offered the most cost-effective means of advancing the pursuit of increased efficiency.

The New Zealand arrangements thus constituted an action of a government suspending its primary tendencies to create a set of governance arrangements that insulated the sector from politically-motivated actions that would dilute the pursuit of efficiency.

\subsubsection{Challenges to Competition Law}

The 'light-handed' regime prevailed until 2001, when it was replaced by an industry-specific regulatory body - the Office of the Telecommunications Commissioner - under the Telecommunications Act 2001. During the period of light-handed regulation, only two Commerce Act actions alleging exertion of a dominant position were brought against the incumbent - one by new entrant Clear Communications in 1991 (Clear case), and one by the Commerce Commission in 1999 (0867 case). After hearings in the High Court ${ }^{1}$, Court of Appeal $^{2}$ and Privy Council ${ }^{3}$, the incumbent was ultimately found in the Clear case not to have acted anti-competitively by including in its interconnection prices to competitors a component

\footnotetext{
${ }^{1}$ Clear Communications v Telecom Corporation (1993) 5 TCLR 166 (HC)

${ }^{2}$ Clear Communications v Telecom Corporation (1993) 5 TCLR413 (CA)

${ }^{3}$ Telecom Corporation v Clear Communications [1994] 5 NZBLC 103, 552 (PC); [1995] 1 NZLR 385 (PC) passim
} 
to recover the costs of the universal service obligation (adoption of the Baumol-Willig Efficient Component Pricing Rule was adjudged to be a legitimate competitive action by the incumbent). The 0867 case is still sub-judice, and pertains to the requirement by the incumbent that all customers of Internet Service Providers (ISPs) not subscribing to an incumbent-managed account (0867 calling prefix) pay 2c per minute for internet traffic over ten hours per month previously provided free of charge under the 'Kiwi Share' free residential local calling obligation. The measure was introduced to counter arbitrage on the basis of interconnection payments between the incumbent and its competitors as a consequence of the growth in volume of internet calls of longer duration than voice calls. Competitors alleged the action was an exertion of a dominant position as it reduced the desirability for ISPs to purchase their connections, but had been approved by the Minister. Price arbitrage was induced principally as a consequence of the universal service 'free calling' obligation, and was putting the incumbent under severe financial duress (Howell, 2007).

It is far from clear that the 'light-handed' New Zealand regime performed any worse over the 1990s than industry-specific regimes using efficiency gains as a benchmark. The New Zealand residential telephony price index fell by more than the OECD average over this period, and free residential dial-up internet telephony access led to the country becoming a world leader in internet connection and use (Howell, 2007). Dynamic efficiency did not appear to be impaired, as the incumbent was one of the OECD's earliest DSL adopters (January, 1999), using a high-speed (2Mbps) service widely available (85\% of the population had access by 2003) priced very low taking speed into account (Howell, 2003). Yet, as the incumbent still held a very large market share, and was clearly charging prices in excess of marginal cost, even if only to recoup universal service obligation costs, a significant number of market participants (principally competitors to the incumbent and opponents of privatisation) urged for the introduction of industry-specific regulation.

\subsubsection{Distribution and Efficiency Implications of Court Decisions}

The justification most commonly cited by proponents of industry-specific regulation was the extent to which the incumbent's prices exceeded marginal cost. This issue, at the core of the Clear case, is in essence a distributional and not an efficiency one. Whilst the High Court and Privy Council both found that Telecom could use ECPR pricing to recover social costs from the "Kiwi Share', the Court of Appeal found that any price including a component of monopoly rent (i.e. above marginal cost) was anti-competitive. 
The implication of the Court of Appeal judgement was that the incumbent alone should bear the costs of the social obligations (a distributional issue). Competitors' costs would therefore be lower than the incumbent's in the areas where the incumbent recovered the costs of the social obligations, making selective entry into low-cost areas more profitable for competitors and making the incumbent's business financially unsustainable (i.e. transferring profits otherwise used by the incumbent to subsidise unprofitable connections into the pockets of competitors). Furthermore, if entrants faced none of the social costs, they could profitably enter in a low-cost area even if their costs exceeded the incumbent's, as long as they fell below the incumbent's prices including the social cost recovery. Such entry would lead to decreases in efficiency, but held favour with the incumbent's competitors and opponents of privatisation who preferred that a disproportionate share of the costs of the social obligations fall on the private sector owners of the formerly government-owned network rather than being spread across the industry and thereby all consumers of telecommunications services irrespective of the identity of the provider.

By contrast, the Privy Council (prevailing) decision preserved existing network investment incentives and ongoing incumbent financial sustainability, by ruling that the incumbent had priced exactly as a competitive firm could be expected to price its products, based upon its opportunity cost. However, in doing so, it enshrined in precedent a pricing rule that could, under certain circumstances, result in less than efficient entry and hence lower product variety in downstream markets (Economides \& White, 1995). The decision was interpreted by some commentators at the time as an example of how court-based pursuit of 'competitive' outcomes might compromise pursuit of the efficiency objectives governing the design of the 'light-handed' regime (Blanchard, 1994a; 1994b, 1995). That is, pursuing competition (the means) compromised efficiency (the end). The proposed solution was not the adoption of full industry-specific regulation, but rather a 'light-handed' process that sat under the Commerce Act and the courts (e.g. an arbitration process) enabling swifter resolution of disputes and with a wider mandate to consider efficiency issues not directly part of court pleadings (Blanchard, 1995).

Following an inquiry in 1995 led by the New Zealand Treasury and the Ministry of Commerce (MoC/Treasury, 1995), the Minister of Communications expressed confidence in the existing system and stated that no changes would be made. The pursuit of economic efficiency as the prevailing sector objective was reinforced at the political level (para 209). 


\section{$2.2 \quad$ Politically-Mandated Review: 2000}

The election of a Labour Party-led coalition government in the November 1999 general election, however, resulted in a change in the prevailing political view regarding industryspecific regulation. In part as an electoral response to entrants' dissatisfaction with the outcomes of the 1991-4 court decisions and popular politicized perceptions of the 'failure' of the 'light-handed' regime to result in reductions in the incumbent's market share and degree of dominance, and in part to differentiate its approach from both the previous Labour government that had introduced 'light-handed' regulation from 1984, and the subsequent National Party and National-led coalition governments that had endorsed it, the Labour Party manifesto for the 1999 election promised reforms to the Commerce Act to tighten controls on firms with a dominant position, and an inquiry into the conduct of both the telecommunications and electricity industries.

\subsubsection{Efficiency Diluted by Distributional Concerns}

The new government stated its policy objective for the telecommunications industry as being "to ensure that the regulatory environment delivers cost efficient, timely, and innovative telecommunications services on an ongoing, fair and equitable basis to all existing and potential users"4. The promised commission of inquiry was established early in 2000, with a brief to address (amongst other issues) "alternative means of establishing interconnection terms and conditions; pricing principles and other terms and conditions (such as service quality standards) for current and future forms of interconnection; processes applying to interconnection negotiations, including dispute resolution and enforcement mechanisms; local loop unbundling; resale of telecommunications services; information disclosure;” ${ }^{5}$ the Kiwi share obligations, the numbering regime, number portability and the development of an information economy, including the impact of, and the effect of regulatory regimes on incentives to invest in, new technologies.

The Inquiry appeared to interpret its brief as expressed in the government policy statement in efficiency-related terms. 'Cost-efficient' was presumed to mean that services are produced "at the lowest cost and delivered to consumers at the lowest sustainable price" (p 11) (i.e. perfect productive and allocative efficiency), 'timely' to mean 'the absence of barriers that would impede the implementation and uptake of innovative services” (dynamic efficiency) and 'ongoing' to mean "that regulation should be forward-looking, robust, durable and consistent over time, and not sacrifice long term gains for short-term considerations" (the

\footnotetext{
${ }_{5}^{4}$ http://www.med.govt.nz/templates/Page___ 16432.aspx\#tor
} 
trade-off between dynamic and static efficiency). However, in doing so, the policy imposed multiple and conflicting objectives. Both static and dynamic efficiency objectives were to be addressed simultaneously, with no guidance given to which should take priority. Moreover, the policy required both efficiency and distributional objectives to also be simultaneously satisfied. "Fair and equitable' was taken to mean "the way in which services are provided, the conduct of the industry players and their interactions”, suggesting weight would be given to competitor equity as well as consumer welfare. The policy was clearly unable to be delivered, and without clear prioritisation criteria, left open considerable scope for the Inquiry itself to be captured by vested interests.

\subsubsection{Which Efficiency: Static or Dynamic?}

It was not surprising, therefore, that Inquiry concluded the incumbent's prices still included elements of prices above cost, so, echoing the Court of Appeal decision, were not perfectly allocatively efficient. The 'light-handed' regime was deemed to have failed to deliver the desired environment articulated in the government policy. Establishment of an industryspecific regulator setting TSLRIC-based prices for a variety of the incumbent's fixed-line services, excluding value-added services such as ADSL $^{6}$, was proposed. Again consistent with the Court of Appeal decision, distributive considerations prevailed in the Inquiry's recommendation that the costs of social obligations be borne by the incumbent alone. Yet, although the Inquiry ignored dynamic efficiency issues in its cost-benefit analysis for establishing the regulatory agency as they were deemed too difficult to quantify, local loop unbundling was rejected primarily as it failed to further the policy's efficiency objectives ${ }^{7}$. Pragmatic political interest-trading rather than principled economic analysis thus appeared to prevail in the recommendations.

\footnotetext{
${ }^{6}$ Regulation of ADSL was excluded because the Inquiry "believes Telecom should be allowed the normal competitive incentive to develop such new services with above-cost returns" and "that a judgement has to be made when considering regulation about the maturity of a market. It is inherently more risky to regulate prices of evolving services than those that are more mature, since regulation focussed on efficient pricing would erode rents that are necessary to spur innovation and rapid deployment of a new technology” (p 64).

7 "Other reasons the Inquiry is not recommending full local-loop unbundling are:

$\S$ it does not seem to offer significant benefits to end users over and above those that could be achieved by requiring Telecom to wholesale its local-loop service in the way recommended by the Inquiry;

$\S$ the objective of local-loop unbundling - competitive delivery of local-loop services - is likely to be achieved in many areas and through a variety of technologies without regulatory intervention;

$\S$ full unbundling may not be exploited in areas where local-loop competition is not likely, given that such investment would ikely be unprofitable in the presence of the Kiwi Share and/or technically infeasible. In these areas, wholesaling or data tail access (leased lines) would give other providers the ability to offer customers a total service; and

$\S$ full unbundling is technically complex and would require Telecom to give up control of parts of its network” (p 64-5)
} 


\subsection{Industry-Specific Regulation with Statutory Efficiency Objectives}

The government chose to give legislative force to almost all of the Inquiry's recommendations in the terms of the Telecommunications Act 2001, thereby reinforcing the compromise of the pursuit of efficiency by the pursuit of other, largely distributional, objectives. A Telecommunications Commissioner was established within the Commerce Commission, and TSLRIC pricing became mandatory for 'designated' services (retail minus pricing was imposed for lower-level 'specified' services), in part addressing the distributional objectives of competitors, albeit with some compromises to dynamic efficiency (Quigley, 2004).

Importantly, however, the costs of the 'Kiwi Share' social obligations were ring-fenced as the Telecommunications Service Obligation (TSO) levied as a charge on all industry participants as determined by the Commissioner, thereby avoiding some of the worst efficiency implications that would have arisen had the Court of Appeal decision not been overturned by the Privy Council. Furthermore, the Act created in Section 18(2) a specific obligation for the Commissioner to take account of efficiency when making decisions and recommendations: "in determining whether or not, or the extent to which, any act or omission will result, or will be likely to result, in competition in telecommunications markets for the long-term benefit of end-users of telecommunications services within New Zealand, the efficiencies that will result, or will be likely to result, from that act or omission must be considered".

The Commissioner's independence from political influence was also potentially safeguarded by inclusion within the Commerce Commission. Under the Crown Entities Act, the Commerce Commission as an Independent Crown Entity (ICE) has the least obligation of any of the Crown Entities (statutory bodies outside of core government departments) to political imperatives. An ICE is required to take account of government directives only where they are specifically required to do so as part of their legislated duties. The intent is to ensure that any such obligations are subject to disclosure and debate, and are only imposed with the approval of parliament. Other ICEs include the Law Commission, the Securities Commission, the Human Rights Commission and the offices of the Police Complaints Commissioner and the Health and Disability Commissioner. Appointments of ICE commissioners are made in the name of the Governor General as Head of State rather than Ministers as agents of government.

The statutory obligation that the Commission's decisions take account of efficiency appeared to suggest that, despite some of the more radical Inquiry recommendations, it was the view of parliament that the efficiency objective remained important, albeit slightly diluted by the 
other provisions of the Act. Combined with the apparent independence of the Commission, it could be interpreted that the changes may have been an attempt to create the type of environment hypothesised above whereby a regulatory body could be charged with pursuing efficiency independent from risk of capture by vested (and especially political) interests. Indeed, at the time it was seen as an 'enlightened' form of industry-specific regulation. The Inquiry panel stated that even its more radical recommendations "would still see New Zealand at very much the light-handed end of the regulatory spectrum, arguably the lightest within the OECD” (p 30).

\subsubsection{The LLU Test: Dynamic Efficiency Prevails}

The enforceability and political acceptability of decisions made using the legislated efficiency mandate were explicitly tested when the Commission undertook its statutory (Section 64) review into local loop unbundling in 2003. The investigation was noteworthy internationally for the fact that it employed a cost-benefit analysis based upon a total welfare decision criterion (the sum of consumer and producer surplus as opposed to consumer welfare alone (Hausman \& Sidak, 2005 - albeit subject to criticisms regarding the exclusion of investment in the model). Dynamic efficiency principles were explicitly applied in making the recommendation ultimately not to proceed with unbundling:

The Commission found that "the overall benefits from unbundling are not sufficiently persuasive to satisfy the Commission that a regulated solution is warranted" ${ }^{8}$. Platform competition (e.g. from wireless networks) was considered likely to evolve and reduce the extent of the incumbent's control of the bottleneck to access (para 788). The experience of LLU internationally had been mixed in respect of increasing broadband penetration (para 792). The high costs of mandatory unbundling were also cited, including the critical point that the incentives for the incumbent to invest would be substantially reduced under LLU, and that this would have very significant effects upon the potential welfare gains for consumers (para 794).

Instead, the Commission recommended accepting an offer by the incumbent to make available a limited bitstream service. Given the incumbent's imminent investment in a Next Generation Network (NGN), a lesser form of unbundled access would enable a limited amount of service-differentiated entry, whilst preserving the incumbent's investment incentives and limiting entrants’ exposure to stranded assets in the event of the NGN resulting

\footnotetext{
${ }^{8}$ Executive Summary, (v).

http://www.comcom.govt.nz//IndustryRegulation/Telecommunications/Investigations/LocalLoopUnbundling/ContentFiles/Docu ments/Finalreportexecutivesummary.PDF
} 
in the bypass of exchanges containing entrants' equipment (Gans \& King, 2004; Covec, 2004; Howell, 2007).

The Minister accepted the Commission's recommendations, apparently endorsing both the methodology used and the conclusions reached. The decision was, however, received with considerable dismay by the incumbent's competitors and other interested parties, who would undoubtedly have preferred a different outcome ${ }^{9}$. For this decision, at least, industry-specific regulation constrained by an explicit efficiency obligation had resulted in an economically rational outcome. However, it also confirmed that, in the absence of any apparent ability to deviate the regulator from efficiency-based decision-making, the emphasis of lobbying would become concentrated in the political arena, thereby increasing the pressure on a less wellinformed decision-maker substantially more susceptible to acting opportunistically to resile from the efficiency criterion in future decisions.

\subsubsection{The Mobile Termination Test: Competition Trumps Efficiency}

The ongoing supremacy of the efficiency criterion was further tested by the Commission's inquiry into mobile termination between 2004 and 2006. The initial inquiry was instigated by the Commissioner, who cited "features of the mobile termination market that give rise to concerns about the exercise of market power by mobile carriers" that had led to "complaints that lack of competition in the mobile termination market means charges for fixed-to-mobile calls in New Zealand are unreasonably high" ${ }^{10}$.

Once again, dynamic efficiency considerations underpinned the cost-benefit analysis which led to a recommendation in June 2005 that mobile termination charges for voice calls on 2G networks, but not $3 \mathrm{G}$ networks, be regulated. The recommendation stated: "the Act does not direct the Commission as to the weight that it should give to efficiencies, as opposed to other considerations. This is a matter for the Commission to consider. Where there are tensions between short-term allocative efficiency and long-term dynamic efficiency, the Commission takes the view that giving greater weight to the latter will generally better promote competition for the long-term benefit of end-users” (para 28). Nonetheless, greater weight was given to distributional considerations in this recommendation than in the LLU case, with consumer welfare, rather than total welfare, providing the decisive criterion.

\footnotetext{
${ }^{9}$ See, for example, iHug's submission to the Minister on the matter http://www.med.govt.nz/upload/5898/tcl-rsp-to-comcom-llurpt-submission040209.pdf

${ }^{10}$ http://www.comcom.govt.nz/IndustryRegulation/Telecommunications/telecommunicationsa18200.aspx
} 
In August 2005, the Minister rejected Commission’s recommendation and ordered a second review be undertaken. The second review was to reconsider "definitional and implementation issues concerning 2G and 3G" and take into consideration "commercial offers made by Telecom and Vodafone following the Commission's final report”"11. The Ministerial redirection appears to confirm that lobbying of politicians was now the preferred method of influencing regulatory decisions.

The second report in April 2006 this time recommended that all fixed-to-mobile voice calls on all technology types be subject to regulation ${ }^{12}$ as "substantial net benefits to end users were likely to arise from making mobile termination a designated access service” (para 32) ${ }^{13}$. The redistributive consumer welfare decision criterion was defended: "where wealth transfers which are sustainable and not themselves conducive to inefficiency are likely to result from a measure promoting competition, the Commission ought to give weight to such transfers in the cost-benefit analysis" (para 34). The inclusion of 3G technologies was justified as deployment had advanced between the first and second decisions to the extent that the Commission considered existing 3G investments to be irreversible.

More surprising, though, was the explicit rejection of the supremacy of efficiency in the Commission's decision-making criteria over distributive considerations - a substantial change from the dynamic efficiency criterion emphasised in the first report. The Commission argued that its statutory authority actually prioritised the pursuit of competition as the prevailing sector objective - a fundamental change in the primary objective.

Specifically, the Commission claimed that the Telecommunications Act created a distinction between the Commerce Act seeking to promote competition by restricting the aggregation of market power and controlling its use (sections 36 and 47), and the regulation of existing market power, as provided for in Part IV. Part IV was deemed to focus upon the net benefit to acquirers - that is, it must take into account "the wealth transfer that occurs in reducing the excessive profits of the regulated party" (para 46) - an apparent acknowledgement of redistribution as the primary purpose of regulatory activity. As the Telecommunications Act was deemed to derive as a consequence of Part IV-type dominance, the Commission was in no doubt that in addressing the tension between the promotion of competition (the means) and the pursuit of efficiency (the end), the Telecommunications Act gave primacy to competition:

\footnotetext{
${ }^{11}$ http://www.comcom.govt.nz//IndustryRegulation/Telecommunications/Investigations/MobileTerminationRates/ContentFiles/D ocuments/Ministers\%20letter\%20to\%20commission.pdf

${ }^{12}$ http://www.comcom.govt.nz/IndustryRegulation/Telecommunications/Investigations/MobileTerminationRates/reportsandsubm issions.aspx

${ }^{13}$ Paragraph references relate to the final, revised report, which summarises the material in all of the preceding draft and final reports.
} 
"where there is a tension between the net public benefits and promotion of competition, the statutory context indicates that the primary consideration is the promotion of competition" (para 47). A paragraph later: "the Telecommunications Act is focused on regulating access to promote competition. It does not provide a mechanism that specifically allows for efficiency considerations to take precedence over the promotion of competition. Nor is there anything in the statutory scheme to suggest that this should be the case".

In light of the imperative in Section 18(2) of the Telecommunications Act that decisions must "consider" "efficiencies that result, or will likely result" from an "act or omission" by the Commission in regulating "competition in telecommunications markets for the long-term benefit of end-users of telecommunication services within New Zealand”, the key appears to be in the Commission's interpretation of what is meant by "consider". For pursuit of competition to override pursuit of efficiency, "consider” must constitute only an obligation to demonstrate that as some part of the decision process, efficiency issues were raised. This would parallel the "consideration" given to submissions by interested parties when coming to a recommendation, as attends other processes such as government consultation exercises. That is, Section 18(2) was deemed to contain no statutory obligation that efficiency considerations should have any material effect upon the final recommendation if, in taking them into account, the pursuit of competition was impaired. The interpretation effectively subjugates an objective criterion recognised in economics as the primary objective of competition law and the principal justification for regulatory intervention (the end) to the pursuit of only one of a range of possible means of achieving that objective (competition although which of the various forms of competition which must be prioritised is itself a subjective matter).

If the Commission's view is accepted as legitimate, then it constitutes an admission that all of the previous Commission decisions prioritising efficiency were based upon an erroneous interpretation of the government's intentions when passing the Act. In the historical context, this view is perplexing given that the Act derived from an Inquiry which gave explicit voice (if not fully implementing) efficiency considerations in making its recommendations, and that the government of the time rejected some of the more radical distributive recommendations of the Inquiry in favour of mechanisms more consistent with the pursuit of efficiency (e.g. overriding the recommendation that the incumbent alone meet social obligation costs in favour of an industry-wide cost allocation). A plausible alternative explanation for the radical departure from previous decision-making precedents is that the prevailing political objectives changed between the passing of the Act in 2001 and the 2006 mobile termination decision, and that as an agent of the political principals, the Commission became subject to pressures to 
resile from its previous prioritisation of efficiency in favour of a set of more politically acceptable criteria. That the Minister, when rejecting the first recommendation, instructed the Commission to take account of alternative offers made to the Minister by the firms facing regulation, appears to offer evidence in support of this view. An acknowledgement of subservience to the Minister is contained in the acknowledgement that ultimately "the role of the Commission is to recommend and it is for the Minister to determine” (para 53).

That the prioritisation of competition over efficiency has occurred in the New Zealand case is not inconsistent with the scenario discussed in section one, whereby indiscriminate prioritisation of competition is a likely consequence of conflict between privatisation objectives and regulatory imperatives. Inappropriate substitution of the means for the end is more likely when the decision-maker is not an economic expert. This line of thinking leads to the conclusion that successive lobbying for redistribution to prevail have successfully led to not just the overturning of the efficiency objective and its replacement with a competition one, but also a fundamental change in the control of regulatory decision-making. Ultimately, it is the Minister and not the Commissioner who exercises regulatory control.

\subsubsection{A Shift in Regulatory Control}

The shift in the balance of regulatory control is confirmed by political rejection in 2007 of even the second recommendation to regulate mobile termination rates ${ }^{14}$, in favour of a set of undertakings by the potentially-regulated firms brokered by the Minister of Economic Development ${ }^{15}$ (the Minister of Communications having declared a conflict of interest as a consequence of a legal dispute with one of the companies facing regulation).

As postulated in Section One, an independent regulatory body charged by legislation with pursuit of efficiency cannot respond as flexibly to attempts to capture its processes for distributional purposes as one with less binding criteria. When the interests seeking to capture the agenda are political principals, the lack of flexibility can be overridden by assumption of regulatory decision-making at the political level as a consequence of the formal power of the political principals. In the New Zealand case, it would seem that a change in political objectives necessitating the replacement of the pursuit of efficiency with the pursuit of competition for some distributive purpose would best explain the abrupt change in decision-making in the second mobile termination decision.

\footnotetext{
${ }^{14}$ http://www.beehive.govt.nz/ViewDocument.aspx?DocumentID=29126

${ }^{15}$ http://www.beehive.govt.nz/ViewDocument.aspx?DoumentID=28525 


\subsection{Political Usurpation of Industry Regulation in the Pursuit of Competition}

Confirmation of the likely political origins of the Commission's change to the pursuit of competition as its primary objective comes from the Labour Party manifesto for the September 2005 general election. The manifesto proclaimed "this Labour-led government has ended the destructive period of ultra-light handed regulation that stifled competition, growth and consumer choice in ICT markets" and promised to "closely monitor and enforce commitments made by Telecom New Zealand ${ }^{16}$ under the local loop unbundling decisions and ensure targets for broadband uptake for the next three years as outlined in the Digital Strategy are met” ${ }^{17}$. The election resulted in a minority Labour-led government with a onemember majority based upon one coalition partner and two minor parties bound by confidence and supply agreements. The primacy of competition as the prevailing political objective for the sector was reinforced by the November speech from the throne outlining the new government's agenda: “with respect to ICT, my government will be advancing policies to ensure that the telecommunications sector becomes more competitive and that we achieve faster broadband uptake in line with our competitors” ${ }^{\prime 18}$.

\subsubsection{Ministry-Led Stocktake and a New Telecommunications Act}

In December 2005, the Ministry of Economic Development began a 'Stocktake' of the telecommunications industry, with its primary focus "the broadband market and our broadband performance as a factor in economic performance” (MED, 2006). Given that the expertise to undertake the investigation lay principally in the Telecommunications Commission, the use of policy ministry to undertake an assessment of industry performance implies a lack of political confidence in the Commission and its processes. It also suggests a lack of certainty that a Commission-led analysis "taking account of" efficiency would deliver a set of recommendations consistent with the government's explicit competition agenda to which it was already committed. It also cannot be discounted that the Ministry was preferred for conducting the review specifically because, unlike the Commission, it is not explicitly bound by a requirement even to take account of efficiency in its analyses.

The Stocktake report (MED, 2006), released in May 2006, is notable for its lack of principled economic analysis (see Howell, 2006 for a detailed discussion). In sharp contrast to Commission's analyses, no cost-benefit analysis was undertaken. The Regulatory Impact Statement accompanying the 'Stocktake' proposals rejects the validity of the Commission's

\footnotetext{
${ }^{16}$ The incumbent

${ }^{17}$ http://www.labour.org.nz/policy/jobs_and_economy/2005policy/Pol05-Comms/index.html

${ }^{18}$ http://www.scoop.co.nz/stories/PA0511/S00104.htm (Despite successive attempts in June 2007 to retrieve the official version from http://www.dia.govt.nz/Pubforms.nsf/NZGZT/Speech187Nov05.pdf/\$file/Speech187Nov05.pdf , it could not be retrieved.). This source appears to have reproduced the text complete, but this fact cannot be verified.
} 
analysis in 2003, but specifically states that no new analysis is necessary to quantify the effects of the recommendations made.

Rather, full local loop unbundling and functional separation of the incumbent were justified primarily on the basis of the broadband market failing to meet an arbitrary level of competitiveness defined by the share of connections sold by competitors to the incumbent ${ }^{19}$, and investment by the incumbent being deemed insufficient on the basis of slippage from an investment schedule proposed in 2003 and an unscientific benchmarking against a handful of other OECD countries. The efficacy of the remedies proposed was supported principally by an unscientific assertion that New Zealand's low broadband uptake was explained principally by the low share of connections sold by competitors (Network Strategies, 2006), unsubstantiated assurances by unnamed OECD officials that LLU would increase both broadband uptake and investment by incumbents and entrants, and a survey of new entrants on their likely investment intentions in the event that LLU was mandated. Submissions on the proposals were heard by a Select Committee comprised of generalist politicians rather than a panel of expert Commerce Commissioners, and were not subject to the three-stage Telecommunications Commission processes of a draft report, a quasi-court conference where the recommendations and written submissions on the draft report by all interested parties can be tested in a contestable manner, and a final report. The process was not subject to appeal or review on either process or substance.

The recommendations were enacted in December 2006. Along with the provisions for full LLU and separation, a new section (19A) was added requiring the Commission to take account of any economic policies of the government that are communicated by the Minister in writing. On face value, this appears to place the requirement to take account of government economic policies on the same footing as the requirement to take account of efficiency in making recommendations as per section 18(2).. If treated as an imperative, as the efficiency obligation was from 2001 to 2005, it would appear to explicitly compromise the independence of the Commission from government by making it an instrument via which government economic policy is enacted. Alternatively, if interpreted in the light of the second mobile termination inquiry, it could be subjugated, but only in favour of the pursuit of competition which, incidentally, was an economic policy of the government that incorporated the requirement in the first place. Rather than clarify the Commission's objectives, it appears

\footnotetext{
${ }^{19}$ On February 2 2006, the Commissioner notified the Minister of Communications that at the end of 2005, whilst the number of ADSL broadband connections sold exceeded the target set in the 2005 agreement with Telecom by $11.6 \%$, only $24.5 \%$, rather than $33.3 \%$ had been sold by competitors to Telecom.

http://www.comcom.govt.nz//IndustryRegulation/Telecommunications/MonitoringandReporting/ContentFiles/Documents/Telco \%20Key\%20Stats\%20-\%20Quarterly\%20Monitoring\%20Report\%20-\%2031\%20March\%202007.pdf
} 
that the new obligation compounds the problem of multiple priorities, and reduces the possibility that any of the objectives will be satisfactorily delivered. Moreover, it creates a further tension if, in the future, government economic policies change again in a manner that brings them into conflict even with the competition imperative (e.g. nationalization of assets).

Togerher, the 2006 Stocktake and Telecommunications Act amendments signal that the New Zealand regulatory process no longer makes any pretence of being independent. The Ministry and politicians were now firmly established, by dint of formal legislative power, as the third party alongside the courts and the Commission in governing industry activities. By extension, it highly unlikely that any of the three considerations deemed important in the consideration of the allocation of regulatory decision-making power to further economic efficiency ends will be brought to bear in future decisions under the current arrangements.

\subsubsection{Overt Ministerial Intervention}

In April 2007, the Minister of Communications released proposals for the functional separation of the incumbent. In May, at the same time as he announced the appointment of a new Commissioner, he revealed that he, and not the Commissioner, would lead the separation process. This was deemed by the Cabinet to "the urgency attached by the government to the need to secure a clear outcome on this matter in the shortest possible timeframe. Because this is a major structural issue and not a matter of micro regulation, this was felt and is still felt to be the appropriate way forward" 20 .

That the New Zealand political principals see the structure of an industry where almost all investment comes from the private sector as the prerogative of political control, whilst the role of regulators is a 'micro' one not only confirms the political assumption of regulatory control, but also is at considerable variance with the prevailing views espoused by the OECD and the ITU that industry-specific regulation be insulated from political processes to the greatest extent possible precisely to guard against the pursuit of short-term self-interested agendas. As Ministerial supervision of separation marks the third time since the 2005 election that the formal political power of the principal in the regulatory agreement was exerted in order to take back control of duties ordinarily in the ambit of a regulatory authority, there is little doubt that Ministerial control is now an embedded structural element of New Zealand telecommunications industry governance.

\footnotetext{
${ }^{20}$ http://www.beehive.govt.nz/ViewDocument.aspx?DocumentID=29595
} 


\section{Conclusion}

The unique New Zealand institutional structure appears to have evolved because the explicit attempts by governments in the past to create arrangements that prioritised the pursuit of efficiency above other considerations, first by the reliance upon competition law alone, and subsequently by explicitly including efficiency objectives in the mandate given to the industry-specific regulator, have ultimately failed to withstand the test of subsequent governments to firstly dilute the force of the efficiency mandate, and ultimately to capture the regulatory process as a means of furthering its own agenda. The erosion of the efficiency mandate began gradually, but has accelerated since 2005 .

The chronology of the erosion illustrates the thesis that, despite the best of intentions, ultimately the governance arrangements are determined by those with the political power to make the laws allocating responsibility for various tasks. Whilst pursuit of efficiency is rationally justifiable from an economic perspective, and it has been demonstrated to be the objective of, if not perfectly achievable via, competition law, explicit inclusion of efficiency in a regulatory objective is not sustainable on the long-run, as the inability of an objective regulator to satisfy the petitions of those seeking to capture the process for their own purposes creates pressure for the law-maker politicians. The supremacy of the efficiency criterion will persist only as long as it is congruent with the political objectives of the government of the day. Governments change, and their objectives change with them. Inevitably and eventually, in the absence of the ability to exercise control informally to capture the process, a successor government which cannot be bound by its predecessors will reverse earlier decisions, using its powers to either change the rules or to take over the regulatory task itself. The only reason that the courts administering competition law can avoid such capture is because their constitutional origins afford them a degree of independence not available to agencies that derive their mandate from political processes.

Given the lack of ability to enforce an efficiency objective in the long-run via industryspecific regulation, the only sustainable means of doing so would appear to be via competition law. Imperfect though its process may be, the New Zealand experiment suggests that, in the absence of constitutional protections for a regulatory agency also charged with the pursuit of efficiency, it may be the only sustainable institutional compromise. 


\section{References}

Alleman, J. \& Rappoport, P. (2005). Regulatory failure: time for a new paradigm. Communications and Strategies 60 pp105-121.

Arnold, T., Boles de Boer, D., \& Evans, L. (2003). The structure of industry in New Zealand: its implications for competition law. In Berry, M. \& Evans, L. (Eds) Competition law at the turn of the century. Wellington, New Zealand: Victoria University Press.

Blanchard, C. (1995). Telecommunications regulation in New Zealand: light-handed regulation and the Privy Council's judgement. Telecommunications Policy 19(6), 456-75.

Blanchard, C. (1994a). Telecommunications regulation in New Zealand: the Court of Appeal's decision in Clear Communications $\mathrm{v}$ Telecom Corporation. Telecommunications Policy 18(9), 725-33.

Blanchard, C. (1994b). Telecommunications regulation in New Zealand: how effective is 'light-handed' regulation? Telecommunications Policy 18(2), 154-64.

Boles de Boer, D., \& Evans, L. (1996). The Economic Efficiency of Telecommunications in a Deregulated Market: the Case of New Zealand. Economic Record, 72(216), 24-39.

Carlton, D., \& Perloff, J. (2005). Modern industrial organization (4 ${ }^{\text {th }}$ ed.). Boston: Pearson/Addison Wesley.

Carlton, D., \& Picker, R. (2007). Antitrust and Regulation. National Bureau of Economic Research Working Paper 12902. Available on http://www.nber.org/papers/w12902.

Commerce Commission. (2003). Telecommunications Act 2001 Section 64 review and schedule 3 investigation into unbundling the local loop network and the fixed public data network Final Report. Wellington, New Zealand. Available on http://www.comcom.govt.nz//IndustryRegulation/Telecommunications/Investigations LLocalLoopUnbundling/ContentFiles/Documents/finalreport.PDF .

Connolly, S., \& Munro, A. (1999). Economics of the public sector. Harlow, Essex: Pearson Education.

Covec (2004). Benchmarking Telecom's UPC service. Available on http://www.comcom.govt.nz//IndustryRegulation/Telecommunications/Investigations /Unbundling-

PartialCircuits/ContentFiles/Documents/Final\%20Draft\%20Report\%20(August\%204 \%202004)\%20-\%20UPC\%20Benchmarking.pdf).PDF .

Crandall, R., Ingraham, A., \& Singer, H. (2004). Do unbundling policies discourage facilities-based investment? The B.E. Journal in Economic Analysis and Policy.

Crandall, R., \& Sidak, G. (2007). Is mandatory unbundling the key to increasing broadband penetration in Mexico? A survey of the international evidence. Criterion Economics. Available on http://ssrn.com/abstract=996065.

Economides, N., \& White, L. (1995). Access and interconnection pricing? How efficient is the "efficient component pricing rule"? Antitrust Bulletin 40(3), 557-79.

Evans, L., Grimes, A., Wilkinson, B., \& Teece, D. (1996). Economic reforms in New Zealand 1984-1995: the pursuit of efficiency. Journal of Economic Literature 34 (December 1996), 1856-1902.

Feldstein, M. (1972a). Distributional equity and the optimal structure of public pricing. American Economic Review 62: 32-36.

Feldstein, M. (1972b). Equity and efficiency in public pricing. Quarterly Journal of Economics 86: 175-87.

Gans, J., \& King, S. (2004). Access holidays and the timing of infrastructure investment. Economic Record 80(248), 89-100.

Guthrie, G. (2006). Regulating infrastructure: the impact on risk and investment. Journal of Economic Literature 44(4), 925-972.

Hausman, J., \& Sidak, G. (2005). Did mandatory unbundling achieve its purpose? Empirical evidence from five countries. Journal of Competition Law and Economics 1(1), 173245. 
Howell, B. (2007). A Pendulous Progression: New zealand's Telecommunications Regulation 1987-2007. Available from http://www.iscr.org.nz.

Howell, B. (2006). Submission: Telecommunications Amendment Bill. Available from http://www.iscr.org.nz.

Kahn, A. (1975). The Economics of Regulation Vol II. New York: Wiley and Sons Inc.

Kahn, A. (1970). The Economics of Regulation Vol I. New York: Wiley and Sons Inc.

Ministry of Commerce \& The Treasury. (1995). Regulation of access to vertically-integrated natural monopolies. Wellington, New Zealand: Ministry of Commerce; The Treasury.http://www.med.govt.nz/templates/MultipageDocumentPage_4560.aspx

Ministry of Economic Development. (2006). Promoting competition in the market for broadband services. Wellington, New Zealand: Ministry of Economic Development. Available on http://www.med.govt.nz/upload/36537/promoting-competition.pdf .

Ministry of Commerce \& The Treasury. (1995). Regulation of access to vertically-integrated natural monopolies. Wellington, New Zealand: Ministry of Commerce; The Treasury.http://www.med.govt.nz/templates/MultipageDocumentPage_4560.aspx

Ministry of Economic Development. (2006). Promoting competition in the market for broadband services. Wellington, New Zealand: Ministry of Economic Development. Available on http://www.med.govt.nz/upload/36537/promoting-competition.pdf .

Peltzman, S. (1976). Toward a more general theory of regulation. Journal of Law and Economics 19: 211-40.

Pindyck, R. (2004). Mandatory Unbundling and Irreversible Investment in Telecom Networks. National Bureau of Economic Research Working Paper 10287. Available on http://www.nber.org/papers/w10287.

Pindyck, R. (2005). Pricing Capital Under Mandatory Unbundling and Facilities Sharing National Bureau of Economic Research Working Paper 11225. Available on http://www.nber.org/papers/w11225.

Quigley, N. (2004). Dynamic Competition in Telecommunication: Implications for Regulatory Policy. Toronto: C.D. Howe Institute Commentary, February.

Schmalansee, R. (1981). The Control of Natural Monopolies. Lexington, MA: Lexington Books.

Sidak, G. (2008). Abolishing the Price Squeeze as a Theory of Antitrust Liability. Criterion Economics. 